\title{
La memoria escenificada. Estetización de la memoria y su función
}

\author{
Claudio Cifuentes-Aldunate \\ Syddansk Universitet
}

\begin{abstract}
Resumen:
El artículo que sigue es una reflexión sobre la escenificación literaria de una memoria. Se presentan dos casos: el relato de Marco Denevi “La historia” y el relato de Antonio Ferres "El exilio del parque". El primer relato se instala en el hecho simple de hacer de la memoria (histórica o personal) un objeto estético, produciendo en el texto una confrontación entre un discurso 'verdadero' por 'cómo se dice' (por elementos retóricos que usa, el de Homero) frente a otro discurso que se jacta de ser verdadero por — precisamente- carecer de adornos (el de Ulises). El arte de relatar y sus estrategias narrativas y retóricas se imponen. Es finalmente lo que el público cree. En el segundo caso un texto nos presenta la memorización de un exiliado español su espacio de infancia (un parque antes de la Guerra Civil) que hoy ha sido cambiado. Hay una confrontación entre la memoria de lo que ese espacio fue y lo que actualmente es (verdadero y falseado, respectivamente). El espacio 'parque' se vuelve simbólico-metonímico de toda la nación española, produciéndose una estetización simbólica en la figura que el relato mismo constituye como totalidad.
\end{abstract}

Palabras clave: subjetividad, verdad, objetividad, estetización, retórica, memoria.

\begin{abstract}
:
The present article is a reflection on the literary staging of a memory. Two cases are presented: Marco Denevi's short story "La historia" and Antonio Ferres" "El exilio del parque". The first is installed in the simple fact of making an aesthetic object of memory (historical or personal), producing a confrontation between a 'true' discourse by 'how it is said' (through the rhetorical elements used) in contrast to another discourse that boasts of being true because it lacks adornments. The art of telling and its narrative and rhetorical strategies finally prevail; it is what the public believes. In the second case, a text presents us with the memorization of a Spanish exile, his childhood space (a park before the Civil War) which today has been transformed. There is a confrontation between the memory of what that space was and what it is today (true and falsified, respectively). The 'park' space becomes symbolic-metonymic of the entire Spanish nation, producing a symbolic aestheticization in the figure that the story itself constitutes as a whole.
\end{abstract}

Keywords: subjectivity, truth, objectivity, aesthetization, rhetoric, memory

La reflexión que sigue se hace cargo de dos relatos cuyo punto de unión es 'el retorno de un Ulises'. Se trata del micro-relato del escritor argentino Marco Denevi, "La historia" (1973), que alude concretamente al Ulises troyano, y el relato del escritor valenciano "El exilio del parque" (1983). En estos relatos observamos dos movimientos contrarios: en Denevi vemos un Ulises que no reconoce la Troya narrada por Homero, y que sufre que su propio relato, de la guerra vivida, venga negado por 
sus auditores por carecer de los artificios que hacen un relato 'verosímil' según los códigos estéticos helenos. En Ferres tenemos otro Ulises: un español retornado del exilio, el cual no reconoce su espacio, ahora cambiado por la modernidad. Aquí el espacio viene reconocido sólo en el momento en que la tierra viene abierta por el bastón de un viejo sentado en el parque. Éste le había negado al retornado que ese espacio de su infancia hubiese sido cambiado.

Mi propuesta, en lo que sigue, es analizar el fenómeno de la estetización ideológica de la memoria. Me refiero aquí a la presencia, en el texto, de un interés ideológico en el hecho de 'hacer bella' la memoria: un hecho de pretensión histórico-legendaria (el retorno de Ulises a Ítaca) se hace visible a través de su estetización en el verso homérico. Este fenómeno se contrasta con quién realmente vivió la guerra de Troya y que no reconoce en esa versificación la realidad vivida. En ese gesto tenemos la omisión estética y/o ideológica de 'la verdad' en éste y otros relatos literarios. Estos relatos juegan intertextualmente con otros y, en su juego, exhiben constantemente ese fenómeno que podríamos llamar 'la irreconocibilidad de la verdad'. Se muestra en estos relatos que una cierta verdad ha sido literarizada y que esa instancia que los clásicos llamaban la inventio, en su práctica retórica, habrían 'deformado' la verdad, como si la verdad literaria existiera como 'otra realidad' más allá de la palabra. Estos textos, como 'versión' de un hecho histórico (Guerra Civil) o versión de un hecho históricolegendario (retorno de Ulises), se constituyen como una 'memoria traicionada', exenta del logos o nódulo fenomenológico que le dio origen. En los relatos que analizaré se encuentra el tema común del retorno de un 'Ulises', un sujeto que dice: 'eso no fue así como tú lo cuentas'. En estos textos hay un enfoque neo-platónico. Lo que el oponente de estos sujetos cuenta, es una realidad 'desvirtuada o degradada' (puesto que está sublimada u olvidada) en relación a un concepto de lo real.

$\mathrm{El}$ acercamiento se concretiza en un análisis semiótico-intertextual que recoge los ideologemas que contienen tanto la estetización literaria así como su movimiento contrario: la depuración del adorno narrativo culpable de 'blasfemia' en el tema tratado (ej. la guerra de Troya) y la posibilidad de representación 'pura' de la verdad. Mi reflexión propone dicha depuración como otra 'versión' retórica: la retórica de la palabra desnuda. Los asideros empíricos de donde surge la reflexión son dos textos unidos por el tema del 'retorno' y un tipo de anti-anagnórisis, donde hay un 'reconocimiento' imposible: El marco teórico de reflexión, en cuanto a memoria, será Elizabeth Jelin, Roland Barthes ("Discurso" y Verosimil) y Tzvetan Todorov; en la reducción eidética (semas/ideologemas), Julien Greimas y Julia Kristeva ("La productividad" y Semiótica); y, en la parte interpretativa, Sigmund Freud.

En un micro-relato del escritor argentino Marco Denevi, que publica en su Antología Precoz, y viene titulado "La literatura" (1973), nos presenta una metáfora de la memoria trastocada, o mejor dicho, 'deformada'. El relato se centra en el inevitable proceso de ficcionalización que padece todo hecho, toda acción, por el sencillo gesto de ser narrados (Barthes, "Discurso" y Verosimil; Jelin).

El carácter ambiguo de la ficción histórica o de las ficciones que contienen 'Historia', hace de ellos un 'decir cuestionable o dudoso', pues junto al suceder ficcional se incrusta un suceder factual. Creo importante retener estos dos conceptos que, en las novelas históricas, memorias y biografías, se fusionan y dejan al texto en un umbral de credibilidad. Por un lado, estos textos — en la contemporaneidad- entran en una práctica escritural que los acerca a los primeros textos de nuestra civilización, mitos y 
leyendas. Eran textos que aún no separaban la 'Historia' de las 'historias', y donde además el elemento factual iba de la mano con el elemento estético, sencillamente 'porque así se narraban los acontecimientos'. Dichos textos, o dichas historias, eran la manera de saber la Historia, allí mezclada con la visión del mundo y de la vida de esa localidad y de ese tiempo, es decir, una Weltanschaunng cronotópica inscripta en los mitos, leyendas, suceder factual, todo mezclado. No obstante, el lector de aquella época (y también algunos más actuales) asumen la lectura de esos textos como poseyentes del carácter intangible de algunos lieux de mémoire de los que nos habla Pierre Nora. Es el carácter monumental de estos textos, que vienen a ser considerados textos epónimos de una nación, de sus orígenes, de sus vicisitudes históricas, lo que hace de ellos la piedra angular sobre la que se cimenta la identidad de una nación. Son las ficciones que, a pesar de ser ficciones, en términos de Benedict Anderson, 'inventan la nación'. A nuestra mente vienen textos como La Araucana, donde Don Alonso de Ercilla cuenta, poetizadamente, la Guerra de Arauco, durante la conquista de Chile, lo mismo sucede con La Ilíada, La Odisea, poetizaciones de la Guerra de Troya y del retorno de uno de sus héroes helenos, etc.

Es precisamente de esta tradición homérica de La Odisea, específicamente del relato del retorno de Ulises a Ítaca, cuando llega a Esqueria, que Marco Denevi toma esta metonimia -o trozo simbólicamente representativo de la totalidad de la memoria histórico-legendaria de la Guerra de Troya. En el hipertexto (Genette) de Denevi, Ulises llega de incógnito hasta Esqueria y, recibido como un extranjero, penetra en el palacio de Alcínoo, donde la corte se ha reunido y escucha - y luego discute- la recién escrita Ilíada de Homero que acaba de cantar el aedo Demódoco. El carácter metonímico (y metatextual) de este pasaje se funda en que es sólo este pasaje del retorno de Ulises donde, constituyendo esa parte del retorno, 'escucha', por el Aedo, el canto homérico de la totalidad de la guerra y su retorno desde Troya. Ulises escucha los comentarios de los cortesanos:

Los jóvenes [...] comentan en voz alta: - Los versos bien medidos. - Las metáforas, brillantes y vigorosas. - El lenguaje, adecuado a las situaciones. - Esto en cuanto a la forma. Analicemos ahora el fondo. - Sobresaliente, a mi juicio, el retrato de Agamenón. Gracioso el episodio de Tersites. (Denevi 200-201)

Se hace evidente que la discusión se centra en la retórica y en la adecuación de las formas retóricas al contenido expresado. En realidad, lo que se discute es la textualización o 'puesta en texto' de una vivencia real para ese auditor llamado Ulises: La guerra de Troya con todos los aderezos que la épica y la versificación helénica exige a tal tipo de textos.

Esa narración ausente, de índole experiencial de la vivencia de Ulises la presenta él mismo, en 'su' propia versión:

Y Ulises piensa: ‘¿Qué es lo que ha cantado Demódoco? ¿A qué Troya se ha referido, a qué griegos? No he reconocido a nadie. Aquellos sudores, aquellas lágrimas, aquellos olores, aquellas voces, aquel fuego, aquel dolor, aquel miedo ¿Dónde están? Ha balbuceado una estúpida parodia. Ahora sabrán estos jóvenes lo que fue Troya.' Ulises comienza a hablar. (Denevi 201) 
El discurso de Ulises a los académicos resulta un desmentido a la narración épica homérica. A la elegancia y la precisión de los versos y de la métrica, Ulises opone lo que podríamos llamar 'la experiencia bélica verdadera', muy lejana a la retórica altisonante y solemne del texto épico. Sin embargo, nosotros debemos emplazarnos como el 'tercer ojo' de la discusión crítica, y ver que, se hace evidente, que el texto de Ulises, que desmiente la retórica épica homérica, no es otra cosa que 'otra retórica', otra manera de textualizar lo vivido, otra manera de presentar la verdad, la narrativa de su vivencia viene dada en un código que podríamos llamar 'realista' donde abunda la sangre, el sudor y las lágrimas. Sin embargo, el texto de Denevi no se cierra aquí, sino con la reacción de los académicos ante este ignorante vagabundo que osó criticar sus comentarios:

- Cállate, extranjero, y cesa de farfullar galimatías. Tu guerra de Troya se parece más a una riña de gallos que a una contienda de héroes. Luego del divino canto de Demódoco, ¿Pretendes tú emularlo con semejante ristra de disparates? (Denevi 201)

'Memoria narrada' o 'vivencia recordada', siempre hay una subjetivación de la vivencia que resulta ser otro tipo de textualización, una puesta en escena que puede contener intencionalidades de muchas índoles: "separado de lo real, el signo (siempre no disyuntivo) se da un falso real mediante la retórica" (Kristeva, Semiótica 113). El ideologema (Kristeva, Semiótica 82; Pérez Iglesias 71) realista de la 'verdad descarnada' se está oponiendo al ideologema aristocrático de la 'elegancia del decir' para creer el decir. ${ }^{1}$ En el caso de Ulises hay una reacción ante lo que yo llamaría 'el sufrimiento borrado', ante lo no-narrado en el proceso de selección inherente a eso de contar un hecho histórico, como lo propone Roland Barthes en "El discurso de la Historia". Allí, Barthes deja en claro que la memoria es siempre un proceso 'agónico' entre el recuerdo y el olvido y su puesta en palabras es siempre un resultado deficiente, incompleto, modificado, con fallas, con omisiones, todo eso mezclado con recuerdos y verdades. En el relato de Denevi se hace evidente un hecho crucial: el proceso según el cual la envoltura estética hace un texto 'creíble' o no. (Según el concepto de 'verosímil semántico' ya trabajado en Semiotiké o Semiótica 1 así como también en un artículo de la antología Lo verosimil, por Julia Kristeva. Se hace evidente cómo, cada época, tiene sus baremos para considerar un texto portador, o no, de una hipotética 'verdad'. Se ha opuesto claramente, por un lado, la retórica helénica y, por otro lado, la narración de Ulises, lo que podríamos llamar una 'verdad' entre comillas, que no es otra cosa que 'la retórica realista’ de la vivencia. Sin embargo, en ambos casos, tenemos dos textos: el texto que se hace 'creíble' por cómo respeta las reglas del 'cómo se deben decir ciertas cosas' (el texto de Homero recitado por el aedo Demódoco) y el texto que se viste de lo que podríamos llamar 'la retórica de la autenticidad y del trauma', la narración de rabia y lloro de Ulises que no se reconoce ni a sí mismo, ni a sus compañeros ni los hechos narrados en la versificación homérica. El detalle que da prestigio de verdad es

\footnotetext{
1 “[e]l concepto de intertextualidad [...] Con esta concepción [...] se concibe el texto como una negación de otro texto, como dialogismo, como ambivalencia, como doble escritura/lectura, como ideologema, como translingüística [...] Y es a través del ideologema que va a ser posible el estudio de los textos incluidos e incluyentes del texto general, de la historia y de la cultura, no como reflejo de la realidad, sino como ideología que se debate dentro del mismo texto que es diálogo de textos." (Pérez Iglesias 71)
} 
evidentemente, en el relato de Denevi, aquel relato imperfecto, farfullado y llorado de ese personaje que 'viene directamente del escenario bélico'. Hay un factor de proximidad y de vivencia, si comparamos con el origen del otro texto, seguramente escrito lejos del suceder bélico, alimentado por otras fuentes culturales y escrito en el deleite de la escritura una tarde de suave brisa bajo los olivos y mirando el mar. Pienso en el hipotético escriba que inmortalizaba los versos de ese ciego llamado Homero.

Aunque hoy, desde el punto de vista crítico-analítico estamos ciertos de que los textos son envoltorios formales de posibles verdades, más que verdades posibles, continúa habiendo en un ámbito amplio de lectores, una comprensión 'inmediata' (o sin filtros) de acontecimientos históricos novelados, aunque los escritores actuales se hayan dado a la empresa de desencantar a los lectores ingenuos que aún sueñan con encontrar verdades fidedignas en textos de orden estético. Es así que, ahora, el acento se traslada a la escenificación de verdades, de uno o varios sujetos, procesadas subjetivamente, donde muchas veces el narrador es un personaje que indaga, y que ya tiene su posicionamiento respecto a la verdad y desea, en su incursión policial, sólo ratificar su hipótesis en un juego de entrevistas y deducciones, donde los entrevistados son otros sujetos que a su vez también tienen 'otras subjetivaciones' de la verdad: verdades filtradas a través de tomas de posición ideológica, de un mal recordar o de un recordar selectivo incompleto y errático. En ese apartado habría decenas de ejemplos y a este respecto, lo más emblemático que mi selectivo recuerdo me trae a la memoria, sería la novelística de Javier Cercas (Soldados de Salamina, Anatomía de un instante), o aquella de Mario Vargas Llosa (Conversación en La catedral, La fiesta del Chivo).

El texto post-moderno/tardo-moderno nos repite constantemente a la imposibilidad de llegar a una verdad total, o sencillamente a una verdad. De esta manera la literatura deja de ser habitáculo para este concepto, y se queda, simple y fatalmente, en 'el juego representacional de buscar la verdad', juego de buscar la verdad visto como una figura neo-retórica de desencanto: una narrativa que confrontada al concepto de 'verdad', abre más incertezas que certidumbres y que insiste en el carácter inalcanzable de la verdad y que desnuda su relación que es más bien con lo verosímil que con la verdad. ${ }^{2}$

Ese buscar 'el lugar de la verdad y de la memoria' lo reencontramos en un pequeño relato del escritor valenciano Antonio Ferres: en su cuento titulado "El exilio del parque", título que es metáfora y personificación del exilio. Ferres nos instala en el retorno a la España ya democrática por parte de un Ulises moderno recién llegado de México. La vuelta a su espacio de juegos de su infancia y la sensación angustiante de 'estar allí y de no encontrar el espacio que recordaba, el espacio que su madre le ordenó recordar.

Se trata, una vez más de un segundo caso de 'memoria negada': aquello no es como yo lo recuerdo o viví. Ya sabemos que los exilios los sufren las gentes. En este caso ese 'saltar afuera', que es el sentido etimológico de la palabra 'exilio', se lo plantea en relación con un lugar: un parque, un parque recordado de la infancia que de alguna manera ha sido 'excluido' de la memoria de la modernidad.

2 "Lo verosímil, sin ser verdadero, sería el discurso que se asemeja al discurso que se asemeja a lo real”. (Kristeva, Semiótica 11) 
"Había terminado la guerra que destruyó el parque." (Ferres 70) Así comienza el relato de Ferres en una metonimia irónica, puesto que indudablemente la Guerra Civil española no sólo destruyó el parque.

Por todo lo que abarcaba la mirada, kilómetros y kilómetros, sólo quedaban esqueletos de árboles quemados, montones negros de carbón de leña en el suelo. Lo vi desde los altos de la Moncloa, cogido de la mano de mi madre. 'Acuérdate bien de que estamos en los altos de la Moncloa, donde los cuadros de Goya de los hombres pasados por las armas, y acuérdate cómo han dejado el parque del Oeste, aquel bosque donde tú jugabas de chico.' Me lo dijo ella el día que nos íbamos a Huesca. Y luego cruzamos a Francia. Y enseguida a México. Me lo dijo mi madre, entonces, y he tenido siempre presentes esos dos parques, el quemado y el de mi infancia, lleno de verdes árboles en medio de esta ciudad tan seca. (Ferres 70)

Tenemos en la escena inicial de este pequeño relato la figura de la madre y la de un niño (narrador futuro de este relato) que recibe la 'orden' de memorizar, la orden de 'recordar un espacio' perdido y destruido. La orden y el espacio se tiñen en su significancia, de semas maternos: protección, autoridad, a lo que se suma el perdido espacio verde, connotando la fecundidad del bosque, todo subrayado por el discurso de la madre.

Un salto hacia el México del exilio nos presenta una voz anónima que anuncia: “"[...] Que todos los exiliados pueden volver cuando gusten, por orden del Rey.' ¿Saben cómo es ahora el Parque del Oeste en Madrid? ¿Si es que existe todavía?” (Ferres 71) Leemos entonces una anónima respuesta: “El Parque del Oeste está repoblado y luce igual que entonces' - me dijeron. Por eso he vuelto." (Ferres 71). Tenemos así, en este relato, un proyecto simple: la recuperación de un espacio del pasado. Sin embargo, la llegada de este Ulises a su Ítaca, la llegada del narrador al parque, presenta lo que podríamos llamar una anti-anagnórisis:

He deslizado mi vista desde la pendiente, ladera abajo, sintiendo un gran ahogo, un vértigo indefinible. Creo que ha sido en el sitio exacto donde me planté de niño con mi madre, para observar. 'Hijos de la chingada' - me daban ganas de decirles, como hablan los mejicanos. Me da gana de gritarlo, y siento mucha rabia, un odio infinito contra el mundo. No, ya sé que nunca jamás nadie va a poder regresar a aquél Parque del Oeste. [...] No es verdad que el parque esté igual al que era. (Ferres 71)

En el acto de recuperación de ese trozo de patria y de pasado, el narrador se da cuenta de la imposibilidad de su recuperación, constata que, al volver, nunca se vuelve a lo mismo. Ha cambiado el espacio del que se ha huido y la peripecia vital también ha producido cambios en el sujeto.

Me doy perfecta cuenta de que es otro parque, mientras bajo la ladera y en seguida subo por una senda entre árboles pequeños, árboles que no son nada en comparación con el apretado y gigantesco bosque que crecía acá. Vuelvo cada día. (Ferres 71)

La desilusión y consiguiente repetición del acto de ver el parque con la esperanza de reconocerlo hace que el sujeto entre en un cierto tipo de obsesión. 
En el recuerdo infantil de ese espacio, el parque toma connotaciones claramente maternas, desfilan descripciones de estrechas y umbrías veredas, de humedad, figuras que reconstruyen constantemente el carácter orgánicamente materno del parque.

Los chicos corríamos entre arbustos, riachuelos y prados. Recuerdo también que había cuevas profundas en las que sentíamos frío y en donde se oía nacer los manantiales. [...] '[...] Y había aquí arroyos con cascadas, frondosos sauces y nogales y grutas con fuentes escondidas' - le digo al viejo que se sienta medio adormilado en la otra punta del banco. (Ferres 72)

La descripción continúa estableciendo lazos de significación con el significado materno del espacio: cuevas profundas, se oía nacer los manantiales, había arroyos, frondosos sauces y grutas con fuentes. Todos estos significantes guardan la concavidad profunda de una matriz, su humedad, y la feminidad en la frondosidad del sauce. (Freud 2217). El deseo de verse confirmado en su recuerdo, le ha hecho describir su recuerdo al señor que se sienta en el otro extremo del banco:

'Está Ud. seguro de lo que dice? Yo casi tengo su edad y no me acuerdo que fuera así, tal vez un poco más grandes los árboles, pero nada más' — dice. 'Viví muchos años en México, pero me acuerdo perfectamente de cómo era el Parque del Oeste.' 'Yo soy asturiano. Por mi tierra sí hay algunos bosques tan frondosos como lo que usted dice. A lo mejor se refiere usted a otra parte de España menos seca.' (Ferres 72)

El episodio adquiere un significado de negación. El viejo -al no compartir la memoria del narrador- posee un estatuto de oponente en el proceso de recuperación del espacio perdido. El viejo abre la posibilidad de un equívoco en el acto de memorizar y deja al memorizante como un embustero. Estamos aquí en el diálogo del texto de la destrucción de España (metonimizada en el parque) contra el discurso del 'aquí nada pasó' ${ }^{3}$. En este proceso, el rol de oponente del viejo con el que comparte el banco, y que niega su recuerdo como confusión o equivocación, se acentúa, cuando leemos en clave simbólica freudiana los elementos que juegan en la escena de la 'negación de lo propio': el parque y su 'atadura semántica' a la madre.

Durante unos minutos lo veo arañar con la garrota el arenoso suelo amarillento el mismo suelo que yo pisé cuando chico. Según está sentado, abre las piernas, y traza rayas en la tierra que yo ocupé cerca de mi madre. Este sí que es el mismo suelo que busca el calor de mis pies. Andaba yo en cuclillas y la arena era igual. Esta arena. Esto sí que no hay quien me lo quite. (Ferres 73; mi subrayado)

La escena viene descrita en su denotación banal y en su connotación profunda. Me he permitido subrayar los pasajes que me van a servir para dar cuenta de la doble lectura de este pasaje. Vemos el enfado del narrador-personaje con el anciano a quien deseaba

\footnotetext{
${ }^{3}$ Dos discursos que me traen la reflexión de Todorov, quien cita a "Corax, primer teórico de lo verosímil [...]: lo verosímil no era para él una relación con lo real (como lo es lo verdadero), sino con lo que la mayoría de la gente cree que es lo real, dicho de otro modo, con la opinión pública. Es necesario que el discurso esté en conformidad con otro discurso (anónimo, no personal), y no con su referente." (Todorov 12). Ese otro, aquí (contra) discurso, en este relato se metonimiza en 'el viejo'.
} 
como testigo corroborante de la existencia del parque perdido de su infancia. Quien debía confirmar su recuerdo le plantea la posibilidad de confusión o fantasía.

A esta negación del recuerdo, que es leída por el narrador como una desterritorialización (Haesbaert 93-94) se suma ahora lo que podríamos ver —en una óptica freudiana - como la violación de la tierra-madre: el viejo — que tiene la misma edad que el narrador, pero que viene llamado 'viejo' - está sentado 'de piernas abiertas' y con la garrota o bastón en medio de sus piernas. Con su fálico garrote penetra la tierra que le está negando discursivamente al narrador. Es al abrir la tierra que el narrador ve esa tierra 'abierta', ve su color interior que sale a la luz y entonces reconoce la tierra de su infancia, su espacio de origen.

Este sí que es el mismo suelo que busca el calor de mis pies. Andaba yo en cuclillas y la arena era igual. Esta arena. Esto sí que no hay quien me lo quite. (Ferres 73)

El lugar — como decíamos - ligado semánticamente al recuerdo de la madre se hace sagrado y propiedad inalienable de su persona. El retornado obtiene su anagnórisis, reconoce su espacio degradado por el tiempo y la modernidad, pero suyo. Este acto de re-territorialización, de reconocimiento, re-lanza al yo a su ejercicio recordante donde el valor semántico de lo materno lo instala en su infancia, casi en la entraña materna:

Iba yo a gatas y agachándome en la misma arena. El cielo arriba, era como de agua, agua entre tupidas ramas de gigantescos árboles que servian de refugio a miles de pájaros. Los caminos amarillos tenían el mismo tacto de tierra en mis rodillas. Me raspaban hasta hacerme sangre. Como las rayas que traza el viejo hipócritamente con la garrota, sin mirarme a la cara. Serpenteaban los caminos entre frondas de matorrales de arbustos y flores olorosas. (Ferres 74; mi subrayado)

El recuerdo lo instala 'agachado', casi fetal y donde el parque y la visión acuática de ese espacio lo propone como un vientre materno donde su seguridad está garantizada. En esa infancia la arena le hacía sangre en sus rodillas y esa sangre viene comparada con la violación simbólica que ejecuta el viejo con su garrota 'que hace sangrar' su tierra, y, por extensión semántica, su madre. De esa constatación se salta al recuerdo y la morfología orgánica femenina de los caminos serpenteantes y el carácter exuberante y fecundo del lugar que lo conecta una vez más con lo materno.

El recuerdo se interrumpe por una réplica del viejo que se ha decidido a hablar.

'Si ha vivido Ud. en México, puede que se confunda con alguna de esas selvas espesas del trópico.' [...] 'Viejo cabrón fascista' — digo entre dientes, para que no me entienda, para que no se de cuenta tampoco cuánto le odio. (Ferres 73)

Allí termina el relato. La anagnórisis exenta de plenitud, por la degradación del espacio, que ha hecho de un lugar de bosques, un espacio de prados y arbustos. El relato se inicia con el enfado del sujeto por este cambio de su espacio originario y ese enfado se manifiesta con un insulto mexicano. Recuperado y reconocido el espacio, hoy degradado, el insulto al viejo, que continúa negando el recuerdo, viene en una clara fórmula peninsular: 'viejo cabrón fascista'. El retorno de este Ulises que no reconoce su Ítaca, encuentra en el parque un representante del olvido, del fascismo que gobernó 
después, en su rol de negador de lo que hubo. El relato nos habla asimismo de un crimen ecológico que la democracia no ha reparado. En la apología del recuerdo, el texto toma el mismo estatuto de los cuadros de Goya, de los hombres pasados por las armas, que le recordó su madre al partir de allí. El relato se suma a ese sentido del arte de perpetuar estéticamente los crímenes que una Historia Oficial quiere callar, aunque sea un crimen tan banal como la definitiva irrecuperabilidad del tiempo y del espacio que se había visto obligado a abandonar.

Como en el primer relato, donde Ulises no reconoce la puesta en palabras de 'su' guerra de Troya, aquí, este Ulises llegado de México, tampoco reconoce su espacio, hasta que una figura de negación —el viejo- penetrando la tierra con su bastón, le permite reconocer la tierra de su infancia rota por la garrota que surge de entre sus piernas, al tiempo que niega que algo pasó allí, que algo fue destruido.

Retomando nuestra introducción, observamos esos dos movimientos contrarios a que nos referíamos: en Denevi vemos un Ulises que no reconoce la Troya narrada por Homero y su propio relato que viene negado por carecer de los artificios que hacen un relato 'verosímil', según los códigos estéticos de la épica. En Ferres tenemos este otro Ulises, español retornado del exilio que no reconoce su espacio sino en el momento en que la tierra viene abierta por el viejo del bastón, que le había negado su espacio. Es allí, que se escenifica la re-territorialización y la relación del espacio perdido con la madre y con el origen. El relato, en su valor estético, retoma un acto de memoria individual y lo hace colectivo, junto con una denuncia que podríamos adjetivar de ecológica: el acontecer del exilio del parque está en la ausencia de la grandeza del verde, de los grandes árboles de su infancia. El diálogo polémico de este texto se enfrenta no sólo con el discurso del 'aquí nada ha pasado' del viejo representante de ese ideologema, también se enfrenta al texto del progreso democrático urbano e industrialista que dice haber reconstruido la España de antes, esa España/Ítaca que este Ulises no reconoce.

Los 'gigantescos árboles', en su valor fálico y protector, remitirían a otra ausencia: por la aliteración sugerida, el exilio 'del parque' es también el exilio 'del padre', figura ausente pero presente por ausencia y por sugerencia de esos vocablos 'parque' y 'padre', que se suman al origen materno simbolizado, ya visto en el relato.

Así llegamos a la funcionalidad de lo estético, aquello que hace que la añoranza de un lugar recordado y destruido por la guerra amplíe su significado en base al empleo de metonimias y personificaciones y carga semántica múltiple en elementos que parecen mono-semánticos.

En Ferres tenemos la personificación de un parque en el exilio, la aliteración 'parque/padre' que nos permite relacionar al parque con un padre ausente (en exilio de la vida) ¿muerto? El recuerdo del parque atado a la madre: exuberancia y fecundidad del espacio de la infancia hoy ausente. La destrucción del parque de la Moncloa como metonimia de la España destruida, el carácter subjetivo que relaciona parque con vientre materno, tierra con madre, viejo sin memoria y sin rabia con fascismo. El fascismo agresivo y usurpador que, con una caña fálica, abre la tierra-madre y que niega la destrucción de ese espacio. Todos estos elementos hacen que la simpleza del relato se haga compleja por todos los virtuemas ${ }^{4}$ significantes de los elementos que lo

4 “au plan connotatif, le virtuème défini comme l'ensemble de sèmes connotatifs, propres à un individu, à un groupe social ou à une société". (Greimas, Courtés 421). 
componen, y que contribuyen a ampliar su significado de 'verdad negada', todo dentro de una forma estética simbólica.

En Denevi el movimiento es inverso. La narración de Homero cantada por Demódoco ha tenido entre el público a Ulises y éste no ha reconocido la guerra que él vivió. El adorno literario y sus figuras — que Ulises propone como falseamiento-en la estética clásica es lo que hace a esa narración 'verdadera'. El relato desnudo de Ulises, propuesto como verdad, es, en su textualidad, otra versión y otra retórica: la del realismo. Aquí tenemos la estetización como mentira o falseamiento, y la desnudez y crudeza como realidad y verdad, para el personaje, pero para nosotros críticos como otra forma estética, la realista.

Se puede concluir que, en estos relatos, la estetización de la memoria adviene en dos niveles: en Denevi el fenómeno se muestra a nivel de enunciado. Es en la historia misma donde se confronta la memoria estetizada (aquella de Homero) y aquella memoria que se auto-concibe como real y verdadera del Ulises 'no escrito'. En Ferrer tenemos, en cambio, una estetización a nivel de enunciación o producción de la escritura, donde la estetización está en el carácter simbólico de lo narrado: la España rota simbolizada en la metonimia del parque perdido de la infancia de un sujeto. La confrontación que tenemos en el enunciado, en ese relato, es la de un lugar borrado por la modernidad y/o por el olvido frente a un recuerdo y búsqueda desesperada del lugar propio del pasado: un parque que es la España pre-guerra. La guerra había destruido el parque...y mucho más.

\section{Bibliografía}

Anderson, Benedict. Imagined Communities. Reflections on the Origin and Spread of Nationalism. London: Verso, 1983.

Barthes, Roland. "El discurso de la historia". Estructuralismo y literatura. Roland Barthes et al. Selección de José Sazbón. Buenos Aires: Ediciones Nueva Visión, 1970. 3581.

Barthes, Roland et al.: Lo verosímil. Buenos Aires: Editorial Tiempo Contemporáneo, 1970.

Denevi, Marco. Antología Precoz: Santiago de Chile: Editorial Universitaria, 1973.

Ferres, Antonio. Cuentos. Madrid: Alianza Editorial, 1983.

Freud, Sigmund. "El simbolismo en el sueño". Introducción al psicoanálisis. Obras Completas vol. 16. Buenos Aires: Biblioteca Nueva/Losada, 1981. 2212- 2225.

Genette, Gerard. Palimpsestes: La littérature au second degré. Paris: Seuil, 1982.

Greimas, Algirdas Julien y Joseph Courtés. Sémiotique. Dictionnaire raisonné de la théorie du langage. Paris: Hachette Université, 1979.

Haesbaert, Rogerio. Mito da desterritorializaçô: do 'film dos territorios' a multiterritorialidade. Rio de Janeiro: Bertrand, 2004.

Jelin, Elizabeth. Los trabajos de la memoria. España: Siglo XXI, 2002.

Kristeva, Julia. "La productividad llamada texto". Lo Verosimil. Roland Barthes et al. Buenos Aires: Editorial Tiempo Contemporáneo, 1970: 63-94. 
Kristeva, Julia. Semiótica 1. Madrid: Espiral/Fundamentos, 1978.

Nora, Pierre (Dir.). Les lieux de mémoire. Paris: Gallimard, 1992.

Pérez Iglesias, María de los Ángeles. "La semiología de la productividad y la teoría del texto en Julia Kristeva". Filosofía y Lingüistica 7.1/2 (1981): 59-77.

Todorov, Tzvetan. "Introducción". Lo Verosimil. Roland Barthes et al. Buenos Aires: Editorial Tiempo Contemporáneo, 1970. 11-15. 